Article

\title{
Radiation Grafting of a Polymeric Prodrug onto Silicone Rubber for Potential Medical/Surgical Procedures
}

\author{
Hector Magaña ${ }^{1}$, Claudia D. Becerra ${ }^{1}$, Aracely Serrano-Medina ${ }^{2}$, Kenia Palomino ${ }^{1}$, \\ Giovanni Palomino-Vizcaíno ${ }^{3}$, Amelia Olivas-Sarabia ${ }^{4}{ }^{-}$, Emilio Bucio ${ }^{5, *}$ and \\ José M. Cornejo-Bravo ${ }^{1, *(\mathbb{D})}$ \\ 1 Facultad de Ciencias Químicas e Ingeniería, Universidad Autónoma de Baja California, \\ Calzada Universidad 14418, Parque Industrial Internacional Tijuana, Tijuana 22390, Mexico; \\ hector.magana@uabc.edu.mx (H.M.); cbecerra30@uabc.edu.mx (C.D.B.); kenia.palomino@uabc.edu.mx (K.P.) \\ 2 Facultad de Medicina y Psicología, Universidad Autónoma de Baja California, Tijuana 22390, Mexico; \\ aracely.serrano@uabc.edu.mx \\ 3 Facultad de Ciencias de la Salud, Universidad Autónoma de Baja California, Boulevard Universitario 1000, \\ Valle de las Palmas, Tijuana 22260, Mexico; gpalomino@uabc.edu.mx \\ 4 Centro de Nanociencias y Nanotecnología, Universidad Nacional Autónoma de México, Apdo. Postal 14, \\ Ensenada 22800, Mexico; aolivas@cnyn.unam.mx \\ 5 Departamento de Química de Radiaciones y Radioquímica, Instituto de Ciencias Nucleares, Universidad \\ Nacional Autónoma de México, Circuito Exterior, Ciudad Universitaria, CDMX 04510, Mexico \\ * Correspondence: ebucio@nucleares.unam.mx (E.B.); jmcornejo@uabc.edu.mx (J.M.C.-B.)
}

Received: 12 May 2020; Accepted: 3 June 2020; Published: 5 June 2020

\begin{abstract}
Silicone rubber (SR) is a material used for medical procedures, with a common example of its application being in implants for cosmetic or plastic surgeries. It is also an essential component for the development of medical devices. SR was functionalized with the polymeric prodrug of poly(2-methacryloyloxy-benzoic acid) (poly(2MBA)) to render the analgesic anti-inflammatory drug salicylic acid by hydrolysis. The system was designed by functionalizing SR films $(0.5 \mathrm{~cm} \times 1 \mathrm{~cm})$ with a direct grafting method, using gamma irradiation $\left({ }^{60} \mathrm{Co}\right.$ source) to induce the polymerization process. The absorbed dose (from 20 to $100 \mathrm{kGy}$ ) and the monomer concentration (between 0.4 and $1.5 \mathrm{M})$ were critical in controlling the surface and the bulk modifications of SR. Grafting poly(2MBA) onto SR (SR-g-2MBA) were characterized by attenuated total reflectance Fourier transform infrared spectroscopy, thermogravimetric analysis, scanning electron microscopy/energy-dispersive X-ray spectrometry, fluorescence microscopy, the contact angle, and the swelling. SR-g-2MBA demonstrated the drug's sustained and $\mathrm{pH}$-dependent release in simulated physiological mediums $(\mathrm{pH}=5.5$ and 7.4). The drug's release was quantified by high-performance liquid chromatography and confirmed by gas chromatography-mass spectrometry. Finally, cytocompatibility was demonstrated in murine fibroblast and human cervical cancer cell lines. The developed systems provide new polymeric drug release systems for medical silicone applications.
\end{abstract}

Keywords: grafting; polymeric prodrug; medical devices; medical/surgical procedures; $\mathrm{pH}$-dependent release; drug delivery

\section{Introduction}

Medical devices are essential to many surgical procedures [1]; therefore, it is important to have implantable devices that help reduce the inflammatory processes caused by tissue lesions or immunological responses, which have the consequence of prolonging a patient's hospital stay [2,3]. 
Another negative effect related to these devices is bacterial or fungal infections either caused by poor sterilization of the device or acquired in hospitals [4-6]. Innovative solutions of the last decade include the development of combination products, which are defined as a combination between a medical device and a drug and which allow for the targeted release of drugs at the surgical site $[7,8]$. The materials used for medical devices include silicone, polypropylene, poly(vinyl chloride), and polyurethanes [9].

Silicone is a material that is widely used in aesthetic surgeries, such as those on the buttocks or breasts. Therefore, controlled drug-release systems (anti-inflammatory, analgesic, or antimicrobial), incorporated or loaded in the silicone, are an attractive strategy for solving the problems associated with these types of medical procedures $[10,11]$.

Gamma radiation (specifically ${ }^{60} \mathrm{Co}$ ) is a technique for medical device modification, and it is used to graft or functionalize polymers on the surface of a device and to achieve drug and enzyme loading/release $[12,13]$. The method is based on the irradiation of the materials with gamma rays, which generates radicals on the surface that initiate the grafting polymerization process (the direct method) [14]. The advantages of this method include avoiding the use of a polymeric chemical initiator and the ability to obtain a sterilized product [15]. This technique has been used with catheters [16], medical gauze [17], and suture-thread modifications [18].

Some polymers that have been grafted onto devices include poly(acrylic acid), poly(vinyl caprolactam), and poly(2-methacryloyloxy-benzoic acid) (poly(2MBA)). The latter is a polymer prodrug that, with the hydrolysis of a labile ester bond on the pendant groups [19], releases salicylic acid for an extended period. Salicylic acid is a drug already known for its activities as an analgesic, anti-inflammatory, antithrombotic, and antimicrobial agent $[20,21]$. This type of polymeric prodrug (of the salicylate family) has been studied in other systems, such as catheters [22], sutures [23], hydrogels [24], tablets [25], and films [26].

These systems expressed antimicrobial activities against certain strains, including Staphylococcus epidermidis, Pseudomonas aeruginosa, and Staphylococcus aureus. The previous results supported the use of polymeric prodrugs of salicylic acid in devices to prevent bacterial colonization and to prevent biofilms from forming on the materials [27].

The objective of this work was to prepare and evaluate a combined product (a medical device-drug), employing the covalent incorporation of poly(2MBA) in silicone that is used for surgical procedures through graft polymerization by gamma radiation. We determined to what extent the radiation dose and monomer concentration (2MBA) were critical in the grafting degree of the functionalization on silicone. The grafted materials (SR-g-2MBA) were characterized by attenuated total reflectance Fourier transform infrared spectroscopy (FTIR-ATR), microscopy (scanning electron microscope/energy-dispersive X-ray spectrometry (SEM-EDX) and fluorescence), thermogravimetric analysis (TGA), and the contact angle.

The kinetics of the salicylic acid release were evaluated at different $\mathrm{pH}$ values, quantified by high-performance liquid chromatography (HPLC), and confirmed by gas chromatography-mass spectrometry (GC-MS). Finally, we evaluated the toxicity of the materials in a cell culture.

\section{Materials and Methods}

\subsection{Materials}

Silicone rubber (SR) (1 mm in thickness) was provided by Goodfellow (HuntingdonUK). We washed the SR with ethyl alcohol for $24 \mathrm{~h}$ to remove the impurities and dried it under a vacuum $\left(60^{\circ} \mathrm{C}\right)$ for $3 \mathrm{~h}$. All the synthesis reagents (methacrylic anhydride, salicylic acid, dimethylaminopyridine (DMAP), dichloromethane, triethylamine, magnesium sulfate, ethyl ether, p-dioxane, ethanol, toluene, and petroleum ether) were from Sigma-Aldrich (San Luis, MO, USA), DMEM medium, fetal bovine serum, streptomycin solution, gentamicin, HPLC acetonitrile and HPLC methanol, and distilled water were used as received Sigma-Aldrich (San Luis, MO, USA). The MTT kit was from Roche (Basel, Switzerland) 


\subsection{Synthesis of $2 M B A$}

The 2MBA synthesis was carried out using a previously reported method [28]. Briefly, methacrylic anhydride $(7.50 \mathrm{~g})$ was added drop-wise to a solution of salicylic acid $(6.91 \mathrm{~g})$ and DMAP $(0.49 \mathrm{~g})$ in $20 \mathrm{~mL}$ of dichloromethane and $8.42 \mathrm{~mL}$ of triethylamine at $0{ }^{\circ} \mathrm{C}$. The organic phase was extracted with ethyl ether, dried with magnesium sulfate, filtered, and finally concentrated in vacuo. The residue was purified with p-dioxane and petroleum ether, and the final product was a white solid that was characterized by FTIR-ATR and $\mathrm{RMN}-{ }^{1} \mathrm{H}$.

\subsection{Grafting Process (SR-g-2MBA)}

SR films $(0.5 \mathrm{~cm} \times 1 \mathrm{~cm})$ were put in contact with the monomer solution (toluene) in glass ampules. The samples were irradiated with a ${ }^{60} \mathrm{Co}$ source in the dose interval from 20 to $100 \mathrm{kGy}$, and the monomer concentration ranged from 0.4 to $1.5 \mathrm{M}$. The films were washed in ethanol to remove the unrealized graft of poly(2MBA) or homopolymers. The modified SR films were dried under a vacuum at $60{ }^{\circ} \mathrm{C}$. Finally, the graft percentage of the films was calculated was using the following gravimetry equation (Equation (1)) [12]:

$$
\text { Grafting }(\%)=\left(\frac{W-W_{o}}{W_{o}}\right)(100)
$$

where $W o$ and $W$ represent the mass of the SR film before and after grafting, respectively.

\subsection{Characterization of SR-g-2MBA Films}

\subsubsection{TGA and FTIR-ATR Analysis}

Thermogravimetric analysis was evaluated with a TGA Q50, TA Instruments (New Castle, DE, USA), under an inert atmosphere, with a temperature range of $25-800{ }^{\circ} \mathrm{C}$ and a heating rate of $10^{\circ} \mathrm{C} / \mathrm{min}$. The SR and modified films (12.1\%, $18.7 \%$, and $31.1 \%$ grafts) were characterized by FTIR-ATR $\left(4000-650 \mathrm{~cm}^{-1}\right)$ using a PerkinElmer Spectrum 100 spectrometer, PerkinElmer Cetus Instruments (Norwalk, CT, USA) with 16 scans.

\subsubsection{SEM-EDX and Fluorescence Analysis}

Cross-sections and surfaces of SR and SR-g-2MBA films $(0.5 \mathrm{~cm} \times 1 \mathrm{~cm})$ were analyzed using a scanning electron microscope, JSM-5300, JEOL (Akishima, TYO, Japan) coupled with energy dispersive X-Ray spectrometry (EDX). Fluorescence microscopy was conducted for the films, using a Nikon Ti Eclipse microscope (Minato, TYO, Japan) and applying a 4',6-diamidino-2-phenylindole (DAPI) filter (10x).

\subsubsection{Contact Angle and Swelling Test}

The contact angle test was performed using a Kruss DSA 100 device (Matthews, NC, USA), in which unmodified and modified films were used. Then, water was dropped on the surface of the films in five different areas of the material to determine the contact angle. Regarding the swelling test, films with and without grafting were placed in $20 \mathrm{~mL}$ of distilled water at room temperature and weighed at different time intervals (15 to $240 \mathrm{~min}$ ). The following equation, Equation (2) [29], determined the swelling percentage:

$$
\text { Swelling }=\left(\frac{W_{s}-W_{d}}{W_{d}}\right)(100)
$$

where $W_{s}$ corresponds to the weight of the swollen film and $W_{d}$ corresponds to the weight of the dry film. 


\subsection{Salicylic Acid Release and Characterization (HPLC and GC-MS)}

SR and SR-g-2MBA $(10-20 \mathrm{mg} ; 0.5 \mathrm{~cm} \times 1 \mathrm{~cm})$ were exposed at $5 \mathrm{~mL}$ of phosphate-buffered saline (PBS) $\left(\mathrm{pH}=5.5\right.$ and 7.4) and incubated at $37^{\circ} \mathrm{C}$ in a Mini Shaker VWR (West Chester, PA, USA) at constant agitation $(100 \mathrm{rpm})$. Sampling was performed at predetermined times. We analyzed the salicylic acid released with an HPLC Ultimate 3000 Thermo Scientific (Waltham, MA, USA) spectrophotometer using UV detection $(296 \mathrm{~nm})$. A Thermo Scientific Hypersil Gold column $\left(250 \mathrm{~mm} \times 4.6 \mathrm{~mm}\right.$ at $\left.45^{\circ} \mathrm{C}\right)$ (Waltham, MA, USA) was used with a mobile phase of acetonitrile and 30:70 PBS buffer, with an isocratic flow of $1.2 \mathrm{~mL} / \mathrm{min}$ and an injection volume of $10 \mu \mathrm{L}$. The salicylic acid concentration was determined by a calibration curve.

The proportion of the grafted drug was determined by Equation (3) [26]:

$$
\text { Salicylic acid }(m g / g)=\left(\frac{\text { Grafting }(\%)}{(100+\text { Grafting }(\%))\left(M W_{2 M B A}\right)}\right)\left(M W_{\text {Salicylic acid }}\right)(1000)
$$

Release profiles were analyzed by zero- and first-order kinetics models using Excel (Microsoft Office).

The presence of the salicylic acid in the release media was confirmed by GC-MS with a gas chromatograph, model TRACE 1310 Thermo Scientific (Waltham, MA, USA), coupled to a single quadrupole mass spectrometer, model ISQ LT Thermo Scientific (Waltham, MA, USA). A portion of the release medium was extracted with ethyl ether, resuspended, dissolved in methanol, and injected into the chromatograph. The temperature of the transfer line was $250^{\circ} \mathrm{C}$, and the ion source temperature was $240{ }^{\circ} \mathrm{C}$. The oven temperature was $120^{\circ} \mathrm{C}$. We started the column heating ramp, maintaining this temperature for $1 \mathrm{~min}$. Then, we raised the temperature to $280^{\circ} \mathrm{C}$ at a speed of $40^{\circ} \mathrm{C} / \mathrm{min}$ and maintained this temperature for $10 \mathrm{~min}$. Helium was used as the carrier gas, with a flow rate of $1 \mathrm{~mL} / \mathrm{min}$.

\subsection{Cytocompatibility Test}

We conducted the cytocompatibility test with human cervical cancer cell line HeLa (ATCC CCL-2) and murine embryonic fibroblast cell line BALB/3T3 (ATCC CCL-163). The tests were performed in 96-well half-area plates with 30,000 cells $\mathrm{mL}^{-1}$ in DMEM medium complement with fetal bovine serum medium $(10 \%)$, streptomycin solution $(1 \%)$, and $10 \mu \mathrm{g} / \mathrm{mL}$ of gentamicin. After $12 \mathrm{~h}$ of incubation, SR and SR-g-2MBA films $\left(0.2 \times 0.25 \mathrm{~cm}^{2}\right)$ were put in contact with the cells and maintained in a humidified atmosphere at $5 \% \mathrm{CO}_{2}$ and $37^{\circ} \mathrm{C}$. The films were removed $24 \mathrm{~h}$ later and an MTT Kit (Roche, Switzerland) was used to quantify the cell proliferation. A negative control was used with cells without films, and all experiments were performed in triplicate. Finally, the absorbances were determined with a microplate reader at a wavelength of $620 \mathrm{~nm}$ Multiskan FC, Thermo Scientific, (Waltham, MA, USA). The cytocompatibility of the films was determined by Equation (4) [26]:

$$
\text { Cytocompatibility }(\%)=\left(\frac{A b s_{\text {Sample }}}{A b s_{\text {Control }}}\right)(100)
$$

Statistical analysis (one-way ANOVA) was performed with GraphPad Prism (San Diego, CA, USA).

\section{Results and Discussion}

\subsection{Synthesis of $S R-g-2 M B A$}

The graft polymerization by gamma irradiation successfully achieved the functionalization of 2MBA on SR (Figure 1A). The experiments showed an increase in the graft percentages at greater irradiation doses, and the maximum graft was at $60 \mathrm{kGy}$ (Figure 1B). The higher gamma irradiation increased the breaking of the covalent bonds in the structure of the silicone films. In consequence, 
there was a higher radical formation to graft 2MBA [30]. The increasing monomer concentrations experiment demonstrated a growth in the graft percentage in the intervals between 0.4 and $1.5 \mathrm{M}$ (Figure 1C). A higher graft percentage was obtained at $1.5 \mathrm{M}(35 \%)$. The films with graft percentages greater than $20 \%$ showed a more whitish appearance and greater rigidity.
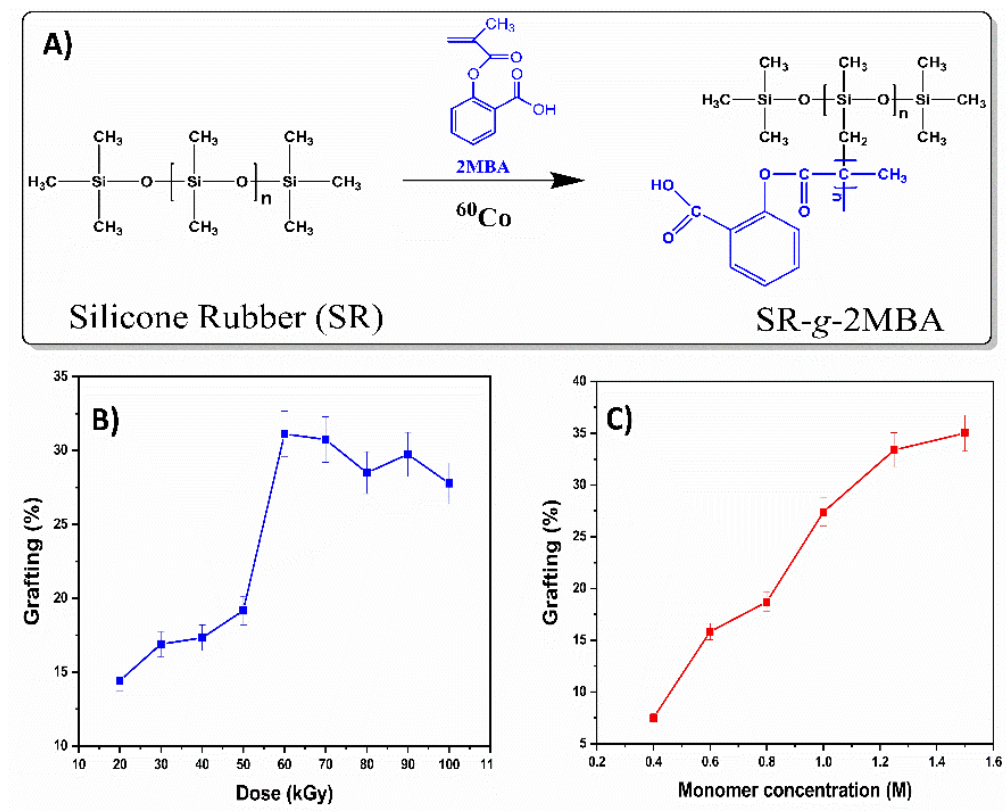

Figure 1. (A) Schematic representation of 2MBA grafting onto silicone rubber (SR); dependence of grafting percentage on (B) absorbed dose and (C) monomer concentration.

\subsection{Characterization of $S R-g-2 M B A$}

\subsubsection{TGA and FTIR-ATR}

We evaluated the thermal stability of SR, poly(2MBA), and (SR-g-2MBA) (Figure 2A). SR presented a thermal degradation at $565{ }^{\circ} \mathrm{C}$ [31], and poly(2MBA) presented two degradations: the first at $220{ }^{\circ} \mathrm{C}$ and the second at $395^{\circ} \mathrm{C}$ [28]. SR-g-2MBA with three different graft percentages $(12.1 \%, 18.7 \%$, and $31.1 \%$ ) showed three thermal degradations. The first and second degradation corresponded to the poly(2MBA) and a higher loss at higher grafting, while the last corresponded to SR. Functionalization of the silicone was also confirmed by infrared spectroscopy (Figure 2B). SR presented three principal bands [32]: $\mathrm{C}-\mathrm{H}, \mathrm{Si}-\mathrm{CH}_{3}$, and $\mathrm{Si}-\mathrm{O}$ at 2978, 1263, and $1000 \mathrm{~cm}^{-1}$, respectively (Figure $2 \mathrm{~B}(\mathrm{a})$ ). The modified films with $12.1 \%, 18.7 \%$, and $31.1 \%$ grafts showed the same signals as SR but also a band at $1735 \mathrm{~cm}^{-1}$, which is characteristic of a carbonyl group $(\mathrm{C}=\mathrm{O})$. This signal belongs to the ester and carboxylic acid group of poly(2MBA) grafted onto SR (Figure 2B(c-e)). At a greater graft (31.1\%), the intensity in the poly (2MBA) bands increased (Figure 2B (b)) and even the double bond of the aromatic region was more apparent. This demonstrates the silicone modification by FTIR-ATR and TGA.

\subsubsection{Contact Angle}

In Figure $2 \mathrm{C}$, we observe that SR has a contact angle of $107^{\circ}$, corresponding to a hydrophobic surface [33]. The films modified with $7.1 \%$ present a contact angle of $91^{\circ}$. This is due to the poly(2MBA) graft that contains polar groups (carboxylic acid and ester), favoring interactions with water [34]. However, films with a graft from $12.1 \%$ to $31.1 \%$ showed an increase in the contact angle (up to $104^{\circ}$ ) due to a large amount of polymer grafted onto the surface. Consequently, the intramolecular interactions were favored and the interactions with the aqueous medium decreased [35]. 

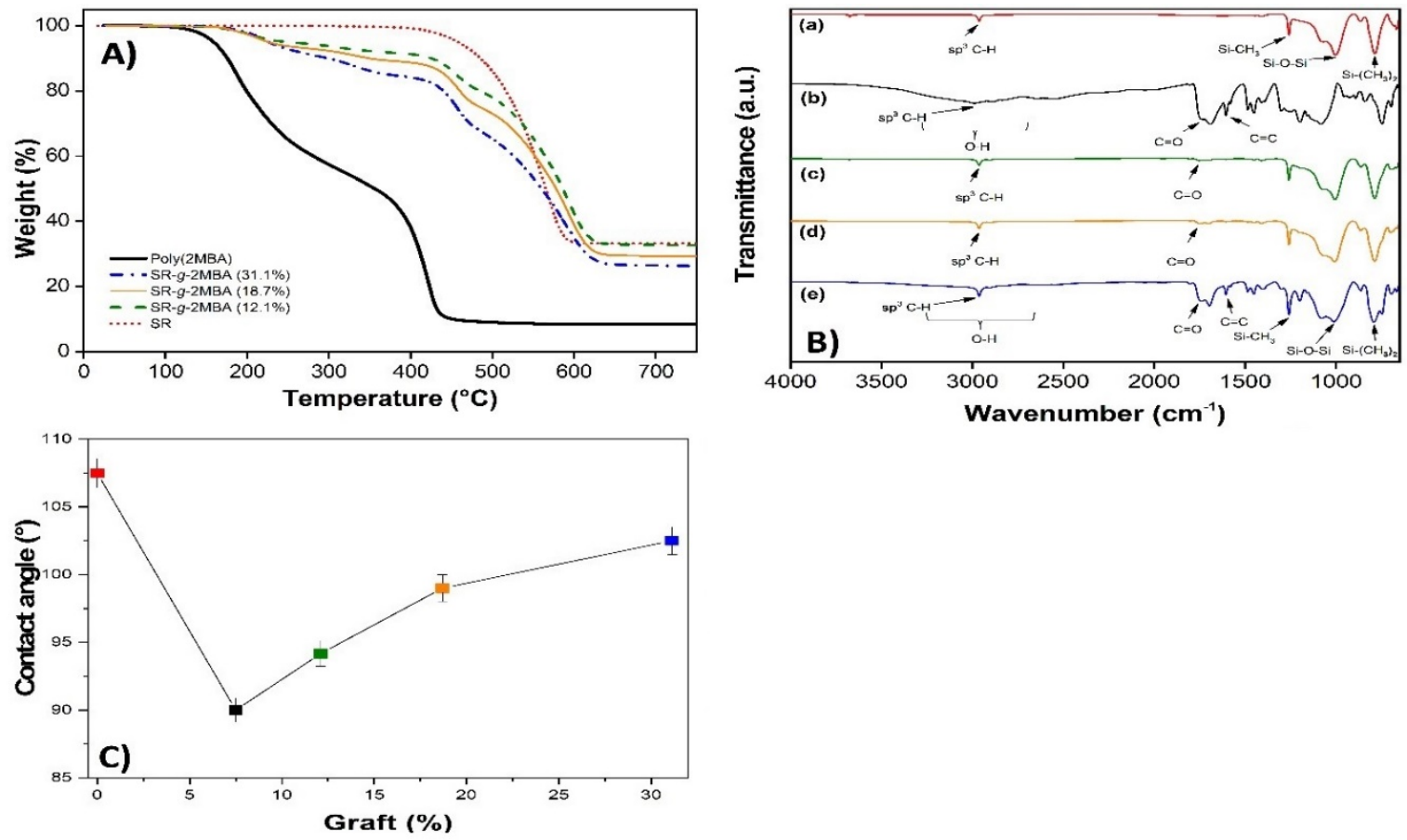

Figure 2. (A) Thermogravimetric analysis (TGA) scans of SR; SR- $g-2 \mathrm{MBA}$ with $12.1 \%, 18.7 \%$, and $31.1 \%$ graft; and poly(2MBA). (B) FTIR-ATR spectra of SR (a), poly(2MBA) (b), SR-g-2MBA 12.1\% (c), SR-g-2MBA 18.1\% (d), and SR-g-2MBA 31.1\% (e). (C) Water contact of SR and SR-g-2MBA with grafting from $7.1 \%$ to $31.1 \%$.

\subsubsection{SEM-EDX and Fluorescence Analysis}

We used scanning and fluorescence electron microscopy to corroborate whether the poly(2MBA) graft was made in bulk or only present on the surface of the SR. Cross-sections of pristine films were observed using SEM and showed homogeneity at the site (Figure 3A). However, in modified films, it was possible to observe sites or areas with differences in the morphology on the cross-section (Figure 3B, rectangle), corresponding to poly(2MBA) grafts in the bulk. There was a distinctive difference between the surface of the films with and without grafting (Figure 3C,D), which confirmed that poly(2MBA) was also grafted over the surface of SR. The similarities with bulk modifications were observed in grafts previously made of methacrylic acid on silicone [29].

Taking advantage of the light-emission properties of salicylate compounds previously reported [36], we performed fluorescence microscopy and observed that SR-g-2MBA film presents fluorescence (blue light), which is indicative of the presence of the salicylic acid derivative and which is not presented by unmodified film (Figure 3E,F). Another complementary test was the EDX analysis, which confirmed the presence of carbon, silicone, and oxygen on the surface of the SR films (Figure 3C). EDX of SR-g-2MBA demonstrated an increase in the proportion of carbon for the poly(2MBA) graft (Figure 3D). 

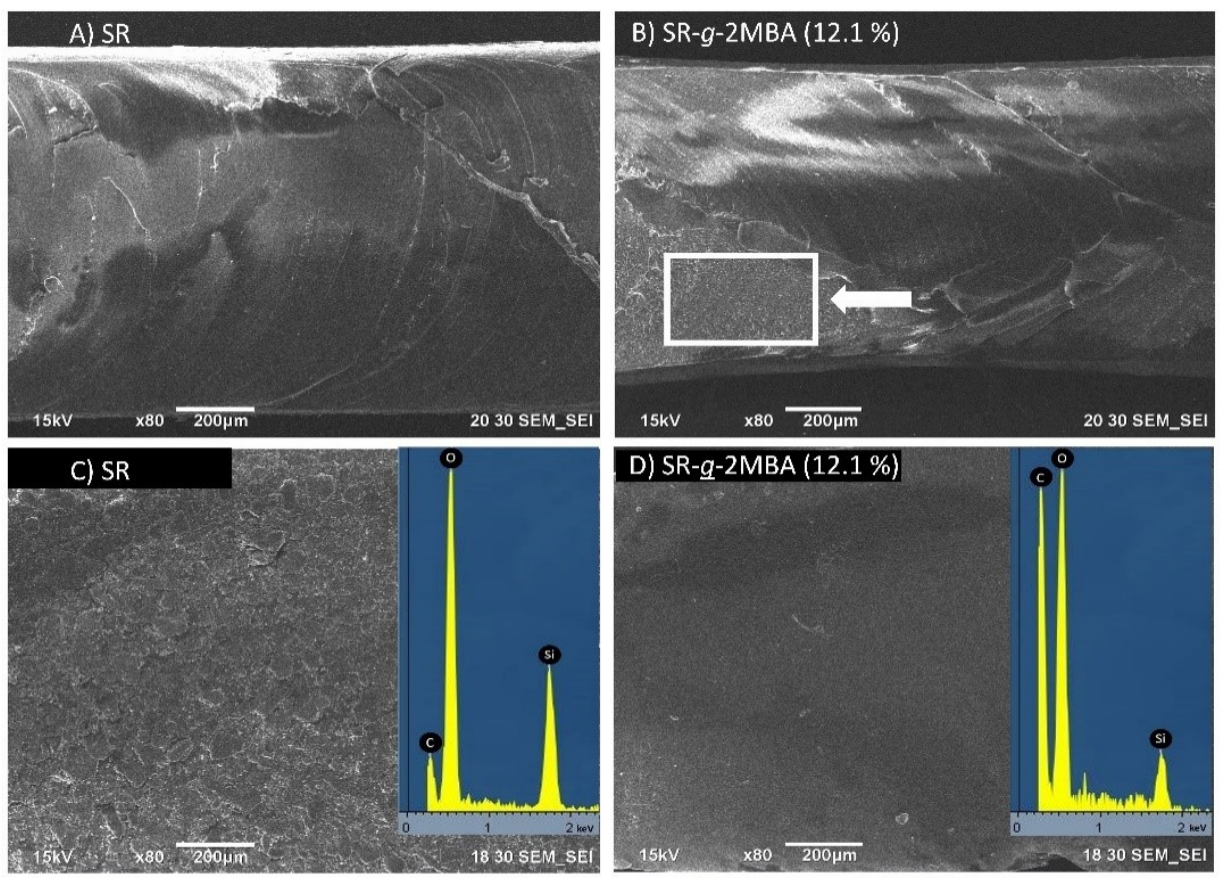

\section{E) SR}

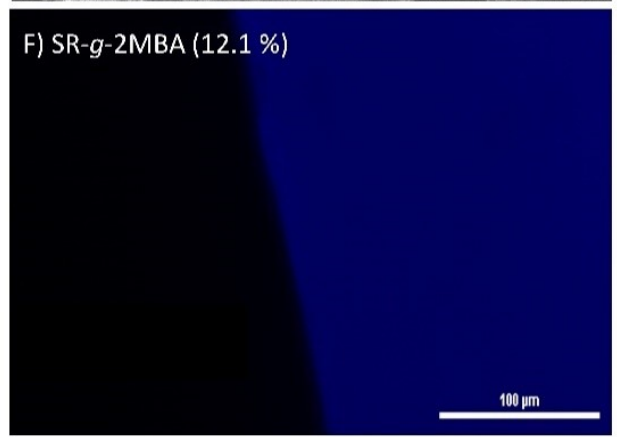

Figure 3. Scanning electron microscope (SEM) images of the cross-sections of (A) SR and (B) SR- $g$-2MBA $12.1 \%$, the surfaces of (C) SR and (D) SR-g-2MBA 12.1\%, and the surface fluorescence emitted by (E) SR and (F) SR-g-2MBA $12.1 \%$. The increase in the intensity of the light emission (blue light) of functionalized film was observed.

\subsubsection{Salicylic Acid Release}

From the release samples, the salicylic acid peak was observed on the HPLC chromatogram (Figure 4) with a retention time of $3.5 \mathrm{~min}$, which is comparable to the retention time of the standard. The release media were taken, diluted with methanol, and subsequently injected into the GC-MS equipment. We observed the salicylic acid molecular ion, with its corresponding mass of $138.12 \mathrm{~g} / \mathrm{mol}$ (Figure 4). The hydrolysis-release rate of salicylic acid from SR-g-2MBA was studied, and it was confirmed that the release was $\mathrm{pH}$-dependent at buffer $\mathrm{pH}$ levels 5.5 and 7.4. A graft film at 7.1\% demonstrated the lowest release rate of salicylic acid, which, at $\mathrm{pH} 5.5$, reached a release of $1.77 \mathrm{mg} / \mathrm{g}$ at $120 \mathrm{~h}$, with an increase in the release of up to $5.4 \mathrm{mg} / \mathrm{g}$ at pH 7.4 (Figure 5). This release difference was due to a higher susceptibility to hydrolysis at alkaline $\mathrm{pH}$, caused by the higher solubility of salicylic acid at higher $\mathrm{pH}$ values $[37,38]$. 

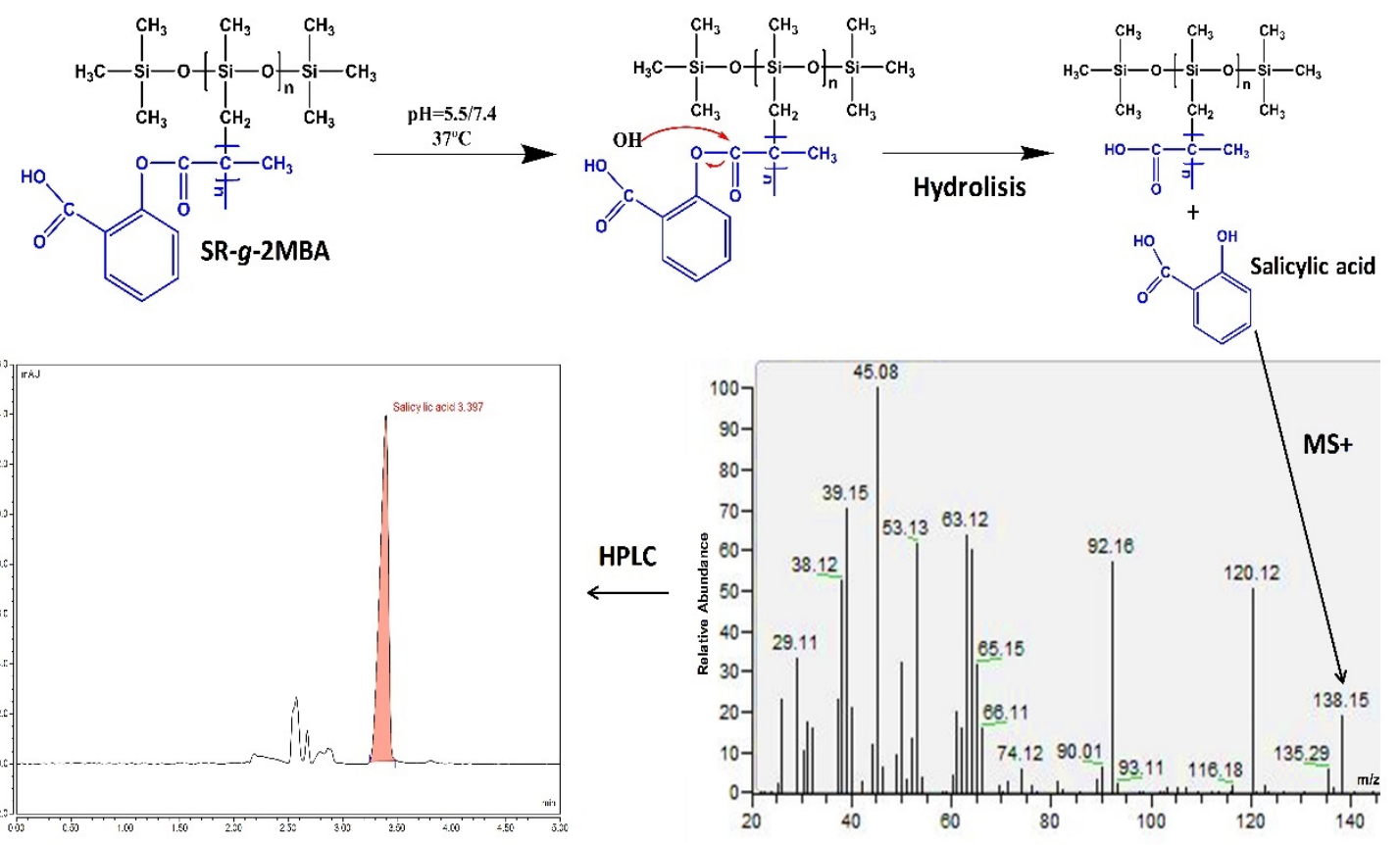

Figure 4. Schematic representation of SR-g-2MBA hydrolysis and salicylic acid release, molecular ion detection, and high-performance liquid chromatography (HPLC) quantification.
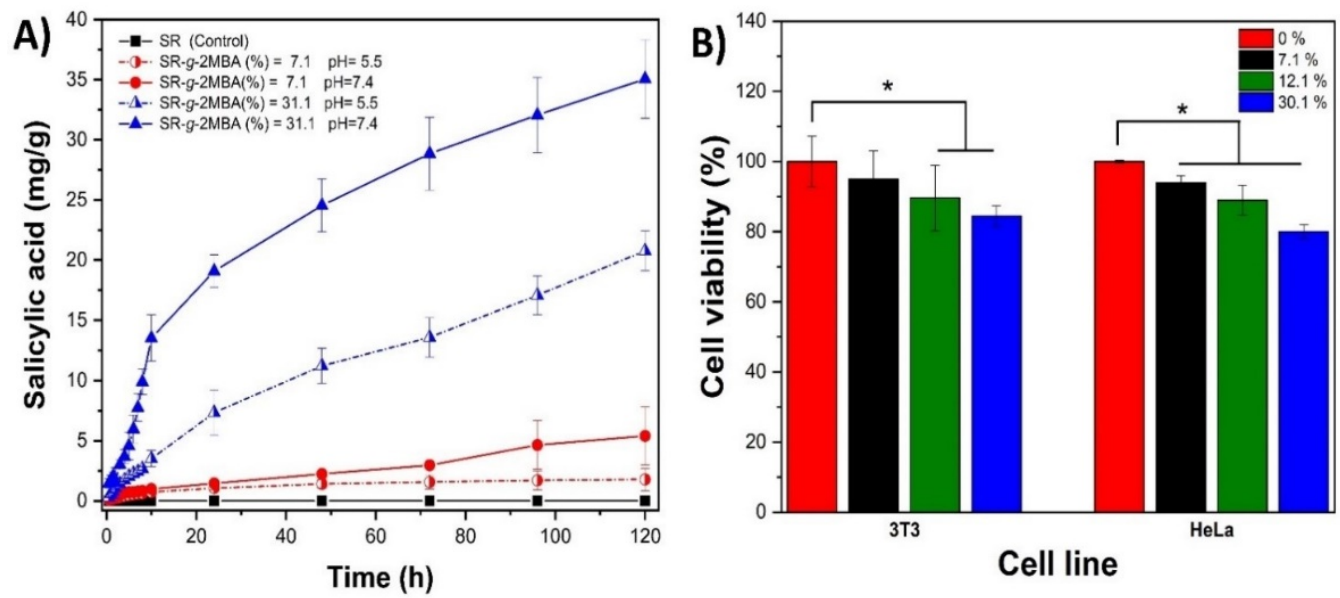

Figure 5. Release profile of salicylic acid from (A) SR-g-2MBA and viability of HeLa and BALB/3T3 cells after $24 \mathrm{~h}(\mathrm{~B})$. The graphs represent the mean and standard deviation from three independent experiments, while the asterisk indicates statistical significance $(p<0.05)$.

Regarding high-graft-level films (31.1\%), a greater drug quantification was observed at $\mathrm{pH}=5.5$ $(20.8 \mathrm{mg} / \mathrm{g}$ at $120 \mathrm{~h})$ and $\mathrm{pH}=7.4(35.1 \mathrm{mg} / \mathrm{g}$ at $120 \mathrm{~h})$. The modified films showed two hydrolysis-release phases. The first was a rapid phase, observed in the first $10 \mathrm{~h}$ of quantification and apparently due to hydrolysis of the grafting surface. The second phase showed a slower rate, corresponding to the grafting within the bulk.

The SR-g-2MBA released films showed zero- and first-order kinetics. The kinetic at a low graft level $(7.1 \%)$ at $\mathrm{pH} 5.5$ was adjusted to a zero-order model, while at $\mathrm{pH} 7.4$ and $31.1 \%$ grafting (both $\mathrm{pH}$ values), it was adjusted to the first order. The kinetic adjustments and release constants can be seen in Table 1. 
Table 1. Release kinetics modeling.

\begin{tabular}{ccccc}
\hline Graft (\%) & Release Medium $\mathbf{p H}$ & Kinetic Model & Rate Constants & $\mathbf{R}^{\mathbf{2}}$ \\
\hline 7.1 & 5.5 & Zero order & $0.0419 \mathrm{mg} / \mathrm{g} \mathrm{h}$ & 0.9853 \\
31.1 & 5.5 & First order & $0.0166 \mathrm{~h}^{-1}$ & 0.9885 \\
7.1 & 7.4 & First order & $0.0513 \mathrm{~h}^{-1}$ & 0.9289 \\
31.1 & 7.4 & First order & $0.0246 \mathrm{~h}^{-1}$ & 0.9986 \\
\hline
\end{tabular}

\subsubsection{Cytocompatibility}

The cytocompatibility of SR-g-2MBA films was evaluated through direct contact with HeLa (human) and BALB/3T3 (mouse) cell lines in small volumes of growing medium. Good cell viability $(>90 \%)$ was demonstrated in low-graft films $(7.1 \%)$ after $24 \mathrm{~h}$ of incubation time for both cell lines (Figure 5). In high-graft films $(12.1 \%$ and $31.1 \%)$, we observed a significant $(p<0.05)$ reduction in the cell viability in both cell lines due to the high salicylic acid concentration released into the cell medium $(47.5 \mathrm{mg} / \mathrm{mL})$, as previously reported by Dasgupta et al. [26,38,39]. These results support future animal studies where factors such as physiological fluids, $\mathrm{pH}$, blood perfusion rate, and volume must be taken into consideration for cytocompatibility [40].

\section{Conclusions}

The incorporation of the polymeric prodrug was achieved on SR by gamma irradiation, where monomer concentration and irradiation dose were key factors in the grafting percentage. Poly(2MBA) was grafted onto the surface and into the mass of the silicone. Salicylic acid was released by hydrolysis in a sustained and $\mathrm{pH}$-dependent fashion, with low-graft-level silicone showing the best cytocompatibility. Gamma radiation is a powerful functionalization process for medical purposes, even though large-scale production would be a challenge. The results are encouraging for further testing of the low-graft-level materials for prophylactic use in handling inflammatory processes and bacterial colonization in cosmetic surgeries. The incorporation of this polymeric prodrug in medical devices or implants for breast reconstructions and augmentations could decrease the mean pain rating (currently 5.9 on a scale of 10), use of analgesics (mean 5.4 days), days off work (mean 6.6), and the 25-day period before returning to normal [41]. Implanting SR modified with the polymer prodrug poly(2MBA) could diminish recovery time, complication rates, and chronic infections.

Author Contributions: Conceptualization, A.S.-M.; methodology, H.M. and C.D.B.; software, G.P.-V.; validation, K.P. and G.P.-V.; formal analysis, A.O.-S.; investigation, A.S.-M.; resources, H.M., A.S.-M., E.B., and J.M.C.-B.; writing-original draft preparation, H.M. and J.M.C.-B.; writing-review and editing, E.B. and J.M.C.-B.; visualization, K.P.; supervision, E.B. and J.M.C.-B.; project administration, J.M.C.-B.; funding acquisition, J.M.C.-B. All authors have read and agreed to the published version of the manuscript.

Funding: This work was funded by SEP's Grant Program to support New Full Time Professors PRODEP 2018 (UABC-PTC-735), New Full-Time Professors PRODEP 2020 (258860 and 255761), Third Special Internal Call for Support to Research Projects (UABC-3902), the 20th Internal Call for Research Project's Funding UABC (3900), and Dirección General de Asuntos del Personal Académico, Universidad Nacional Autónoma de México under Grant IN202320.

Acknowledgments: The authors acknowledge the technical support of the staff at ICN-UNAM (Benjamín Leal, Martín Cruz, and Enrique Palacios).

Conflicts of Interest: The authors declare no conflict of interest.

\section{References}

1. Muskens, I.S.; Gupta, S.; Hulsbergen, A.; Moojen, W.A.; Broekman, M.L.D. Introduction of Novel Medical Devices in Surgery: Ethical Challenges of Current Oversight and Regulation. J. Am. Coll. Surg. 2017, 225, 558-565. [CrossRef] [PubMed]

2. Zitnik, R.J. Treatment of chronic inflammatory diseases with implantable medical devices. Ann. Rheum. Dis. 2011, 70, 67-71. [CrossRef] [PubMed] 
3. Anderson, J.; Cramer, S. Perspectives on the Inflammatory, Healing, and Foreign Body Responses to Biomaterials and Medical Devices; Elsevier Inc.: Amsterdam, Netherlands, 2015; ISBN 9780128005002.

4. Almalki, M.A.; Varghese, R. Prevalence of catheter associated biofilm producing bacteria and their antibiotic sensitivity pattern. J. King Saud Univ. Sci. 2020. [CrossRef]

5. Khatoon, Z.; McTiernan, C.D.; Suuronen, E.J.; Mah, T.F.; Alarcon, E.I. Bacterial biofilm formation on implantable devices and approaches to its treatment and prevention. Heliyon 2018, 4, e01067. [CrossRef]

6. Ceresa, C.; Fracchia, L.; Williams, M.; Banat, I.M.; Díaz De Rienzo, M.A. The effect of sophorolipids against microbial biofilms on medical-grade silicone. J. Biotechnol. 2020, 309, 34-43. [CrossRef]

7. Boutrand, J.P. Methods for the Characterization and Evaluation of Drug-Device Combination Products, 2nd ed.; Elsevier Ltd:: Amsterdam, Netherlands, 2020; ISBN 9780081026434.

8. Lewis, A.L. Sensitive Combination Products: Devices, Pharmaceuticals, and Biologics; Elsevier Inc.: Amsterdam, Netherlands, 2020; ISBN 9780128050828.

9. Sastri, V.R. Material Requirements for Plastics used in Medical Devices. Plast. Med. Devices 2010, 33-54. [CrossRef]

10. Bizjak, M.; Selmi, C.; Praprotnik, S.; Bruck, O.; Perricone, C.; Ehrenfeld, M.; Shoenfeld, Y. Silicone implants and lymphoma: The role of inflammation. J. Autoimmun. 2015, 65, 64-73. [CrossRef]

11. von Hanstein, H.; Horch, R.E.; Schubert, D.W. Resistance of silicone breast explants under cyclic compressive load as a function of implantation time and explant mass. Polym. Test. 2020, 84, 106377. [CrossRef]

12. Costoya, A.; Velázquez Becerra, L.E.; Meléndez-Ortiz, H.I.; Díaz-Gómez, L.; Mayer, C.; Otero, A.; Concheiro, A.; Bucio, E.; Alvarez-Lorenzo, C. Immobilization of antimicrobial and anti-quorum sensing enzymes onto GMA-grafted poly(vinyl chloride) catheters. Int. J. Pharm. 2019, 558, 72-81. [CrossRef]

13. López-Saucedo, F.; Flores-Rojas, G.G.; López-Saucedo, J.; Magariños, B.; Alvarez-Lorenzo, C.; Concheiro, A.; Bucio, E. Antimicrobial silver-loaded polypropylene sutures modified by radiation-grafting. Eur. Polym. J. 2018, 100, 290-297. [CrossRef]

14. Melendez-Ortiz, H.I.; Díaz-Rodríguez, P.; Alvarez-Lorenzo, C.; Concheiro, A.; Bucio, E. Binary graft modification of polypropylene for anti-inflammatory drug-device combo products. J. Pharm. Sci. 2014, 103, 1269-1277. [CrossRef] [PubMed]

15. Pino-Ramos, V.H.; Meléndez-Ortiz, H.I.; Ramos-Ballesteros, A.; Bucio, E. Radiation Grafting of Biopolymers and Synthetic Polymers; Elsevier Inc.: Amsterdam, Netherlands, 2018; ISBN 9780128104620.

16. Zuñiga-Zamorano, I.; Meléndez-Ortiz, H.I.; Costoya, A.; Alvarez-Lorenzo, C.; Concheiro, A.; Bucio, E. Poly(vinyl chloride) catheters modified with $\mathrm{pH}$-responsive poly(methacrylic acid) with affinity for antimicrobial agents. Radiat. Phys. Chem. 2018, 142, 107-114. [CrossRef]

17. Hiriart-Ramírez, E.; Contreras-García, A.; Garcia-Fernandez, M.J.; Concheiro, A.; Alvarez-Lorenzo, C.; Bucio, E. Radiation grafting of glycidyl methacrylate onto cotton gauzes for functionalization with cyclodextrins and elution of antimicrobial agents. Cellulose 2012, 19, 2165-2177. [CrossRef]

18. García-Vargas, M.; González-Chomón, C.; Magariños, B.; Concheiro, A.; Alvarez-Lorenzo, C.; Bucio, E. Acrylic polymer-grafted polypropylene sutures for covalent immobilization or reversible adsorption of vancomycin. Int. J. Pharm. 2015, 461, 286-295. [CrossRef]

19. Agrawal, N.; Agrawal, N. Polymeric Prodrugs: Recent Achievements and General Strategies. J. Antivir. Antiretrovir. 2015, 1, S15-007. [CrossRef]

20. Madan, R.K.; Levitt, J. A review of toxicity from topical salicylic acid preparations. J. Am. Acad. Dermatol. 2014, 70, 788-792. [CrossRef]

21. Cao, Y.; Uhrich, K.E. Salicylic Acid-Based Poly (anhydride-esters): Synthesis, Properties, and Applications; American Chemical Society: Washington, DC, USA, 2018.

22. Nowatzki, P.J.; Koepsel, R.R.; Stoodley, P.; Min, K.; Harper, A.; Murata, H.; Donfack, J.; Hortelano, E.R.; Ehrlich, G.D.; Russell, A.J. Salicylic acid-releasing polyurethane acrylate polymers as anti-biofilm urological catheter coatings. Acta Biomater. 2012, 8, 1869-1880. [CrossRef]

23. Marisol Arteaga-Luna, M.; Hugo Pino-Ramos, V.; Magaña, H.; Bucio, E. Polymeric pro-drug sutures for potential local release of salicylic acid. Int. J. Polym. Mater. Polym. Biomater. 2018, 67, 792-799. [CrossRef]

24. Demirdirek, B.; Uhrich, K.E. Novel salicylic acid-based chemically crosslinked pH-sensitive hydrogels as potential drug delivery systems. Int. J. Pharm. 2017, 528, 406-415. [CrossRef]

25. Erdmann, L.; Uhrich, K.E. Synthesis and degradation characteristics of salicylic acid-derived poly (anhydride-esters). Biomaterials 2000, 21, 1941-1946. [CrossRef] 
26. Magaña, H.; Palomino, K.; Cornejo-Bravo, J.M.; Díaz-Gómez, L.; Concheiro, A.; Zavala-Lagunes, E.; Alvarez-Lorenzo, C.; Bucio, E. Polymeric prodrug-functionalized polypropylene films for sustained release of salicylic acid. Int. J. Pharm. 2016, 511, 579-585. [CrossRef] [PubMed]

27. Price, C.T.D.; Lee, I.R.; Gustafson, J.E. The effects of salicylate on bacteria. Int. J. Biochem. Cell Biol. 2000, 32, 1029-1043. [CrossRef]

28. Licea-Claveríe, A.; Rogel-Hernández, E.; Lopéz-Sanchez, J.A.; Castillo-Arámbula, L.A.; Cornejo-Bravo, J.M.; Arndt, K.F. A facile synthesis route for carboxyaryl-methacrylates: A way to obtain aromatic polyelectrolytes. Des. Monomers Polym. 2003, 6, 67-80. [CrossRef]

29. Vázquez-González, B.; Meléndez-Ortiz, H.I.; Díaz-Gómez, L.; Alvarez-Lorenzo, C.; Concheiro, A.; Bucio, E. Silicone rubber modified with methacrylic acid to host antiseptic drugs. Macromol. Mater. Eng. 2014, 299, 1240-1250. [CrossRef]

30. In Jeong, S.; Park, S.C.; Park, S.J.; Kim, E.J.; Heo, H.; Park, J.S.; Gwon, H.J.; Lim, Y.M.; Jang, M.K. One-step synthesis of gene carrier via gamma irradiation and its application in tumor gene therapy. Int. J. Nanomed. 2018, 13, 525-536. [CrossRef]

31. Segura, T.; Burillo, G. Radiation modification of silicone rubber with glycidylmethacrylate. Radiat. Phys. Chem. 2013, 91, 101-107. [CrossRef]

32. Guo, T.; Pei, Y.; Tang, K.; He, X.; Huang, J.; Wang, F. Mechanical and drug release properties of alginate beads reinforced with cellulose. J. Appl. Polym. Sci. 2017, 134, 1-9. [CrossRef]

33. Magaña, H.; Palomino, K.; Cornejo-Bravo, J.M.; Alvarez- Lorenzo, C.; Concheiro, A.; Bucio, E. Radiation-grafting of acrylamide onto silicone rubber films for diclofenac delivery. Radiat. Phys. Chem. 2015, 107, 164-170. [CrossRef]

34. Bennett, A.J. The absorption of globular proteins. Biopolymers 1973, 12, 1671-1676. [CrossRef]

35. Hameed, N.; Guo, Q.; Hanley, T.; Mai, Y.W. Hydrogen bonding interactions, crystallization, and surface hydrophobicity in nanostructured epoxy/block copolymer blends. J. Polym. Sci. Part B Polym. Phys. 2010, 48, 790-800. [CrossRef]

36. Karim, M.M.; Lee, H.S.; Kim, Y.S.; Bae, H.S.; Lee, S.H. Analysis of salicylic acid based on the fluorescence enhancement of the As(III)-salicylic acid system. Anal. Chim. Acta 2006, 576, 136-139. [CrossRef] [PubMed]

37. Marcus, F.; Colaizzi, J.L.; Barry, H. pH effects on salicylate absorption from hydrophilic ointment. J. Pharm. Sci. 1970, 59, 1616-1620. [CrossRef] [PubMed]

38. Chandorkar, Y.; Bhagat, R.K.; Madras, G.; Basu, B. Cross-linked, biodegradable, cytocompatible salicylic acid based polyesters for localized, sustained delivery of salicylic acid: An in vitro study. Biomacromolecules 2014, 15, 863-875. [CrossRef] [PubMed]

39. Dasgupta, Q.; Chatterjee, K.; Madras, G. Controlled Release of Salicylic Acid from Biodegradable Cross-Linked Polyesters. Mol. Pharm. 2015, 12, 3479-3489. [CrossRef] [PubMed]

40. Chandorkar, Y.; Bhaskar, N.; Madras, G.; Basu, B. Long-term sustained release of salicylic acid from cross-linked biodegradable polyester induces a reduced foreign body response in mice. Biomacromolecules 2015, 16, 636-649. [CrossRef]

41. Rochlin, D.H.; Davis, C.R.; Nguyen, D.H. Breast augmentation and breast reconstruction demonstrate equivalent aesthetic outcomes. Plast. Reconstr. Surg. Glob. Open 2016, 4, 1-8. [CrossRef]

(C) 2020 by the authors. Licensee MDPI, Basel, Switzerland. This article is an open access article distributed under the terms and conditions of the Creative Commons Attribution (CC BY) license (http://creativecommons.org/licenses/by/4.0/). 